\title{
To What Extent is Internet Activity Predictive of Psychological Well-Being?
}

This article was published in the following Dove Press journal:

Psychology Research and Behavior Management

\author{
Sonia Lippke (D) \\ Alina Dahmen ${ }^{2}$ \\ Lingling Gao' \\ Endi Guza' \\ Claudio R Nigg ${ }^{3}$ \\ 'Department of Psychology \& Methods/ \\ Focus Area Diversity, Jacobs University \\ Bremen gGmbH, Bremen, 28759, \\ Germany; ${ }^{2}$ Dr. Becker Klinikgruppe, \\ Cologne, 50968, Germany; ${ }^{3}$ Institute of \\ Sport Science, University of Bern, Bern, \\ 3012 , Switzerland
}

Background: Healthy internet activity (eg, making use of eHealth and online therapy) is positively associated with well-being. However, unhealthy internet activity (too much online time, problematic internet use/PIU, internet dependency/ID, etc.) is associated with reduced well-being, loneliness, and other related negative aspects. While most of the evidence is correlational, some research also shows that internet activity can be predictive for well-being. Objective: The aim of this article is to elaborate on the question as to what extent internet activity is predictive of psychological well-being by means of (a) a scoping review and (b) theoretical understanding which model the interrelation of internet activity and psychological well-being.

Methodology: We searched different electronic databases such as Web of Science by using the search terms "Internet" OR "App" OR "digital" OR "online" OR "mobile application" AND "Use" OR “Activity" OR "Behavior" OR "Engagement" AND "Well-being” OR "Loneliness" for (a, the scoping review) or CCAM for (b, the theoretical understanding).

Results: The scoping review (a) summarizes recent findings: the extent to which internet activity is predictive for well-being depends on the internet activity itself: internet activity facilitating self-management is beneficial for well-being but too much internet activity, PIU and ID are detrimental to well-being. To understand (b) why, when and how internet activity is predictive for well-being, theoretical understanding and a model are required. While theories on either well-being or internet activity exist, not many theories take both aspects into account while also considering other behaviors. One such theory is the Compensatory Carry-Over Action Model (CCAM) which describes mechanisms on how internet use is related to other lifestyle behaviors and well-being, and that individuals are driven by the goal to adopt and maintain well-being - also called higher-level goals - in the CCAM. There are few studies testing the CCAM or selected aspects of it which include internet activity and well-being. Results demonstrate the potentials of such a multifactorial, sophisticated approach: it can help to improve health promotion in times of demographic change and in situations of lacking personnel resources in health care systems.

Conclusion and Recommendation: Suggestions for future research are to employ theoretical approaches like the CCAM and testing intervention effects, as well as supporting individuals in different settings. The main aim should be to perform healthy internet activities to support well-being, and to prevent unhealthy internet activity. Behavior management and learning should accordingly aim at preventing problematic internet use and internet dependency. Keywords: compensatory carry-over action model, CCAM, eHealth, app, mobile applications, online/digital behavior, social media

\section{Plain Language Summary}

Internet activity facilitating self-management is beneficial for well-being but too much internet activity, problematic internet use and internet dependency are detrimental for well-being.
Correspondence: Sonia Lippke Jacobs University Bremen gGmbH, Campus Ring I, Bremen, D-28759, Germany

$\mathrm{Tel} / \mathrm{Fax}+49421$ 200-4730

Email s.lippke@jacobs-university.de

Psychology Research and Behavior Management 2021:14 207-219 
The Compensatory Carry-Over Action Model (CCAM) describes mechanisms on how internet use is related to other lifestyle behaviors and well-being, and that individuals are driven by the goal to adopt and maintain well-being.

Future research should test theoretical approaches, intervention effects experimentally to prevent problematic internet use and internet dependency, and how to improve well-being.

\section{Introduction}

Psychology research and behavior management focus on different aspects relating to the psychology of behavior, the research to explain the psychological basis of behavior or inactivity and the modification of behavior. This can entail self-management but of course also how to help others to change predictors of behavior such as intention and behavior itself. ${ }^{1-3}$ Behavior can be managed by internet activities, directly and indirectly - with positive and negative effects. However, the nature of this relationship is rather unclear at this point. Therefore, this review aims to answer the question: to what extent is internet activity predictive of psychological well-being?

Accordingly, this review will first set the stage with defining well-being; then we review the current state of the science regarding their interrelation and the potentials of internet interventions for behavior management and promotion of well-being. While much research can be found on this topic, a high proportion of studies lack a proper theoretical context. Consequently, we also describe a theoretical model, which can help to explain and predict these associations between internet activity, other behaviors and well-being. The review will close with recommendations for further psychology research and implications for behavioral management practice.

\section{Well-Being}

The concept of well-being is a multidimensional construct that has often been used interchangeably with "happiness" in colloquial terms as well as in the scientific literature (eg, Diener). ${ }^{4}$ While interest in well-being research keeps growing, attempts at describing well-being mostly focus on its dimensions rather than a unified definition. Shin and Johnson were among the first to clarify the concept of well-being by defining it as "a global assessment of a person's quality of life according to his own chosen criteria." ${ }^{\prime 5}$ (p78) Seligman ${ }^{6}$ further argued that although happiness (or positive emotion) is a key component, it is just one of the five pillars of well-being, along with engagement, relationships, meaning and achievement.
According to Diener's ${ }^{4}$ model, subjective well-being consists of three separate but interrelated components: positive affect, negative affect, and life satisfaction; and these indicators can help to track happiness over time. Affective well-being is an important indicator of mental health along with other behavioral components, as positive mental health is exhibited through emotional, psychological, and social well-being. ${ }^{7}$

Empirical research has identified multiple determinants of well-being that may affect mental and physical health. For instance, positive well-being has been associated with lower cardiovascular risk $^{8}$ and lower risk of depression (particularly in younger adults). ${ }^{7}$ Independent living and physical mobility are also important aspects of well-being that may increase one's feelings of self-reliance, autonomy, self-esteem, and purpose in life. ${ }^{9,10}$ Furthermore, skillful, informational, and learning-oriented internet use has been found to positively affect psychological and social well-being. ${ }^{9}$

Low levels of well-being, on the other hand, are related to negative physical and psychological outcomes in general. Scientific evidence shows strong links between low levels of well-being and many other variables such as psychosocial problems, increased levels of suicidal intent, depression, and anxiety (particularly in individuals with cognitive deficits), social isolation, loneliness, ${ }^{11,12}$ poor self-regulation skills ${ }^{13}$ and addictive behaviors. ${ }^{14}$ Thus, a low level of psychological well-being is an important factor for the development of psychological disorders. Relatedly, problematic internet use and internet (gaming) addiction have been found to negatively affect psychological and social well-being. ${ }^{15,16}$

\section{Internet Activity and Psychological Well-Being - Association and Prediction}

Internet activity such as searching for information, maintaining communication and experiencing services provides utility and convenience for individuals. ${ }^{17}$ Internet activity also appears in form of Apps or mobile application usage, online or digital behavior and "social media" engagement. ${ }^{17}$ While the link from social media (such as Facebook) used to pure quantitative social interaction is given, ${ }^{18}$ evidence also shows that users who spend many hours online are at risk for dependency which counteracts well-being. ${ }^{19}$ Also, just more social contact does not mean better social integration and good communication: with 
interaction mediated by the internet (ie, computermediated communication and relationships) the quality of communication might be limited due to reduced stimuli including no physical contact and experiences, eg, no smell cues, no option to touch and limited possibilities to observe the full body which is key for nonverbal communication. Thus, individuals miss out on important aspects of communication and interaction (like haptic cues) and their well-being might be decreased. ${ }^{20}$ Furthermore, it is well known that the outcomes of well-being, physical and psychological health are related to behavior. ${ }^{21}$

To make better use of the advantages that the internet brings to individuals and to avoid the negative effects, many studies have tested the links between internet activity and psychological well-being: investigations have shown that the internet improves psychological wellbeing through smartphone applications (Apps) and online behavior engagement that promotes an individual's work, education, behavior and daily life. ${ }^{22,23}$ For instance, a cross-sectional study has found that online information seeking is positively related to life satisfaction, and this association becomes stronger with the increase of internet skills. ${ }^{9}$ Moreover, a longitudinal study has indicated that using the internet for communication was associated with lower depression and better life satisfaction. ${ }^{24}$

Some studies argue that even for social network sites that have been found to promote psychological well-being this benefit differs across age groups: old adults benefit more from directed communication activities and less from having a large network, compared to young adults. $^{25}$ A longitudinal study conducted by Szabo et $\mathrm{al}^{26}$ concluded three purposes of internet use (social, instrumental, and informational) in promoting well-being. Social use of the internet can indirectly impact well-being via decreased feelings of loneliness and increased social engagement. Informational and instrumental uses indirectly impacted well-being through engagement in a wider range of activities. ${ }^{26}$

Recent studies have found that, in facing emergency health threats such as the COVID-19 pandemic, the internet plays a significant role - it helps to keep physical distancing by means of meeting, counseling or even consultation and therapy, eg, in video-calls or providing films instead of conducting in-person sessions. This can prevent communicable diseases (eg, the COVID-19 virus) from spreading, as well as preventing a complete breakdown of all businesses and social connections. ${ }^{27,28}$
However, previous research has also found that problematic internet use is related to anxiety, perceived stress and social disconnectedness phenomena such as loneliness and Hikikomori (social withdrawal syndrome). This may negatively influence mental health and well-being. ${ }^{15,29}$ Specifically, problematic Facebook use has been found negatively correlated with well-being in a meta-analysis. ${ }^{30}$ Moreover, a cross-sectional study that distinguished leisuretime internet use and work-time internet use revealed that leisure-time internet use, but not work-time internet use, was positively associated with problematic internet use. ${ }^{15}$

To summarize, there is a substantial body of research on both positive and negative aspects that internet activity is associated with psychological well-being or predicts it from various perspectives, such as seeking information, maintaining relationships with others, supporting work and providing entertainment. However, only a few studies have used appropriate theoretical backgrounds explicitly. A better and more comprehensive understanding of the association between internet activity and well-being should also take other behaviors (eg, physical activity or offline social participation) into account. This is important because the different behaviors impact each other and determine well-being in concert. Such activities are the already described offline social activities $^{25}$ and health behaviors or lifestyle which will be described in the following.

\section{Multiple Behaviors}

Research suggests that health behaviors and unhealthy/risk behaviors often cluster or co-occur with the main behaviors smoking, nutrition, alcohol consumption and physical activity (abbreviated to SNAP). ${ }^{21,31,32}$ Multiple health behavior prevalence rates can have a strong impact on cancer-risk and preventable diseases including mental or psychosomatic disorders. ${ }^{33}$ Another example of multiple behavior prevalence is type 2 diabetes: the incidence of this highly prevalent disease is strongly associated with risk behaviors (such as unhealthy nutrition, physical inactivity, unhealthy body weight), which leads to an up to 2.6 times increased mortality. ${ }^{34}$ When unhealthy behaviors co-occur, negative health outcomes multiply ${ }^{21}$ and health-care as well as disability costs increase. ${ }^{35,36}$

However, this burden can be minimized by replacing risk behaviors (such as sedentary behavior while working on the the computer) with components of a healthy lifestyle (ie, physical activity, healthy eating). Individuals at risk for chronic diseases or with present disabilities like 
type 2 diabetes would have better well-being if they changed their unhealthy behaviors: mechanisms of changing multiple health behaviors include increased confidence in changing one behavior, which may, in turn, lead to greater success in changing a second behavior. These cascades can result in improving multiple behaviors, improved health and well-being.

To improve one or multiple behaviors, individuals need to understand the connection between their behavior and their mental and somatic well-being. This so-called health literacy was found to be suboptimal in the general population globally ${ }^{10,37}$ and could be effectively addressed by internet activity. The same holds true for self-regulatory processes: individuals who know that they should change and who have the intention to change their behavior oftentimes suffer from the so-called intention-behavior gap. ${ }^{3}$ To bridge this gap and to overcome situational challenges (such as lack of self-confidence, time, and external support), internet-delivered assistance - also called eHealth or mHealth - can potentially be helpful.

\section{Effectiveness of Internet-Delivered Interventions}

Internet-delivered health interventions and eHealth/ mHealth apps can facilitate behavior change, especially if technology like personal computers, internet, and telephone-delivered interventions is used effectively. ${ }^{38-40}$ In particular, if individuals are unable to come to an intervention at a treatment site because they live in a remote location, have physical limitations or regional orders restrict commuting (eg, due to the COVID-19 pandemic), eHealth is very valuable. ${ }^{10,26}$ Moreover, eHealth interventions can mimic personal support much better than other modes or technologies such as brochures, phone calls or merely posters. Both synchronous and asynchronous solutions provide advantages and disadvantages, for instance the ones outlined in Table 1.

Thereby eHealth with synchronous and asynchronous components can provide the platform for internet activity beneficial for well-being due to its effective ingredient related to counseling and therapeutic settings. ${ }^{41}$ In general, the internet can deliver such interventions by means of expert systems without actual human support (but instead by artificial intelligence and algorithms set up by individuals or generated by machine learning). ${ }^{42,43}$ Alternatively, interventions can be delivered by human experts, too, in terms of the real expert (like a trained counselor or psychotherapist) meeting with the client via the internet synchronously. ${ }^{44}$ Especially in times of lack of therapists and the need to reduce physical contact (due to the need to prevent the spread of viruses such as the SARS-CoV-2) it is necessary to develop and establish internet-based interventions as one component of the therapy and support systems. Such synchronous intervention can provide significant options to overcome disadvantages (Table 1).

Especially for the treatment of psychological disorders, there are several studies that underline the usefulness of

Table I Advantages and Disadvantages of Synchronous and Asynchronous Internet Activities

\begin{tabular}{|c|c|c|}
\hline & $\begin{array}{l}\text { Synchronous (Online Group Session with Real } \\
\text { Other Group Members and Moderator) }\end{array}$ & $\begin{array}{l}\text { Asynchronous (Online Expert System with Automated } \\
\text { Tailoring and Individualization, Contact with a Real } \\
\text { Counselor Only Demand-Driven, eg, via Email) }\end{array}$ \\
\hline \multirow[t]{2}{*}{ Advantage } & \multicolumn{2}{|l|}{ Decentralized, high accessibility, motivation through new media } \\
\hline & $\begin{array}{l}\text { - Group processes/dynamics can be used: group mem- } \\
\text { bers support each other through direct contact in } \\
\text { group actions } \\
\text { - Individualization through the possibility to give direct } \\
\text { feedback in group actions } \\
\text { - Addressing the individual is possible during the session } \\
\text { instantly }\end{array}$ & $\begin{array}{l}\text { - User can choose spontaneously and flexibly the time of the con- } \\
\text { sultation independently of other individuals and the counselor } \\
\text { - User can stop in between and continue later (eg, if computer } \\
\text { crashes or time conflicts) } \\
\text { - Cost-optimized maintenance of the execution after implementation } \\
\text { - If applicable, group processes through blogs and social media (com- } \\
\text { parable to Facebook) }\end{array}$ \\
\hline Disadvantage & $\begin{array}{l}\text { - Timing: if the user is hampered, s/he "misses" the ses- } \\
\text { sion or parts of it } \\
\text { - Cost-intensive implementation through technical } \\
\text { requirements, and counselor training, fees, participant } \\
\text { support, etc. }\end{array}$ & $\begin{array}{l}\text { - Cost-intensive development of the expert system } \\
\text { - Overuse/PIU/ID difficult to detect and to prevent } \\
\text { - Cost-intensive technical requirements }\end{array}$ \\
\hline
\end{tabular}


computer-based interventions to support the standard therapy consisting of psychological and pharmaceutical therapy. ${ }^{35,45-47}$ This is important regarding the high and still rising prevalence of psychological disorders (eg, in Germany each year $27.7 \%$ of the adult population are affected by psychological disorders ${ }^{48,49}$ and the resulting needs of therapies facing a lack of personnel resources.

Regarding the therapy of chronic physical diseases, Weymann et $\mathrm{al}^{50}$ conducted a Randomized Control Trial (RCT) examining the effectiveness of a web-based tailored interactive health communication application (IHCA) on knowledge and empowerment. They focused on patients with type 2 diabetes or chronic low back pain, in comparison to a control system. The authors found that participants spent more time with the tailored system (mean = 51.2 minutes) than with the control program (mean $=37.6$ minutes; $\mathrm{p}<0.001$ ). Participants reported more knowledge on the subject matter and an improvement of their emotional well-being at follow-up. No main effects were found, however, on other dimensions of empowerment and decision-related outcomes. This study showed that individuals are willing to use interactive health communication for changing unhealthy behavior. Also, a metaanalysis by Lustria et $\mathrm{al}^{41}$ found that tailored interventions led to significantly greater improvement in health outcomes compared with control groups. This actually points to the value of tailored over non-tailored interventions.

In eHealth interventions and online psychotherapy or counseling, well-being and behavior change can be effectively addressed by providing personalized input building up health literacy and self-regulatory competencies. ${ }^{10,37}$ However, behavior management is challenging, especially if more than one behavior needs to be altered. ${ }^{31,51}$ The same holds true, if the risk occurs that internet activity is drifting into unhealthy behavior, eg, spending time online in social networks but not being in full resonance with individuals in $\operatorname{situ}^{22}$ or losing control of spending time online (adopting PIU or ID) and not performing health behaviors such as physical activity.

From a health perspective, behaviors need to be improved in orchestration. For example, interventions should improve both, physical exercise and social activities, not just one or the other. ${ }^{12}$ The positive effects of online interventions can only be accomplished when several criteria are met. Firstly, the individual is able to use information technology, and secondly, the individual has obtained enough general and health-specific literacy to fully comprehend and retain the online information sources. $^{37}$ Different meta-analyses have investigated which behaviors can be changed successfully by internetbased interventions. There are numerous meta-analyses clearly demonstrating the effectiveness of those internetbased interventions (e.g., ${ }^{40,52}$ ).

Overall, eHealth interventions can change behaviors, but those changes appear quite small. In terms of offering valuable health information and support; however, they are highly appreciated amongst willing individuals who intend to improve their own well-being. Current pieces of evidence will be summarized in the following.

\section{Aggregation of the Current Evidence on the Extent of Internet Activity Being Predictive for Psychological Well-Being}

A scoping review was performed to research the aim of this article to elaborate on the question as to what extent internet activity is predictive of psychological well-being. No systematic review or meta-analysis was planned at this stage of research because a scoping review appeared more appropriate to broadly summarize the state of the science and to integrate qualitatively the very diverse aspects into one joint perspective. We searched different electronic databases, namely, Web of Science Core Collection, PsycINFO, Pubmed, Cinhal, Medline, and Google Scholar by using the search terms "Internet" OR "App" OR "digital" OR “online” OR “mobile” AND "Use” OR “Activity” OR "Behavior” OR "Engagement" AND "Well-being” OR "loneliness". Only meta-analyses or systematic reviews were included. The hits were scanned to identify if the publications would fit this scope. Thirty-one meta-analyses and five reviews were identified as fitting and are summarized in Table 2 and Supplementary Table 1. The publications included aggregated data from experimental or intervention designs, or correlational studies. Some of the reviews included predictive studies as well. The findings were then classified into the following categories: internet activity predicted positive effects on well-being (22 aggregations), internet activity revealed no relationship with well-being (in 5 publications), internet activity had a negative relationship with well-being (11 aggregations) and internet dependency predicted a negative relationship with well-being (4 aggregations; see Table 2).

While positive effects on well-being were revealed by interventional studies, negative effects were only observed in terms of investigating whether individuals 
Table 2 Synthesis of Current Evidence on the Interrelation of Internet Activity with Psychological Well-Being

\begin{tabular}{|c|c|c|c|c|c|c|c|c|c|}
\hline Primary Author (Citation) & Year & $\mathbf{M}$ & $\mathbf{R}$ & $\mathbf{E}$ & C & IA+ & IAO & IA- & ID- \\
\hline Brown et $\mathrm{al}^{53}$ & 2016 & 1 & & 1 & & I & & & \\
\hline Carolan et $\mathrm{al}^{54}$ & 2017 & 1 & & 1 & & I & & & \\
\hline Chan \& Chen ${ }^{55}$ & 2019 & 1 & & 1 & & I & & & \\
\hline Cheng \& $\mathrm{Li}^{56}$ & 2014 & 1 & & & 1 & & & & I \\
\hline Cheng et $\mathrm{al}^{57}$ & 2018 & 1 & & & 1 & & & & I \\
\hline Choi et $\mathrm{al}^{58}$ & 2012 & 1 & & I & & 1 & 1 & & \\
\hline Cikrikci $^{19}$ & 2016 & 1 & & & 1 & & & I & \\
\hline Cowpertwait \& Clarke $\mathrm{e}^{59}$ & 2013 & 1 & & 1 & & I & & & \\
\hline Davies et $\mathrm{al}^{60}$ & 2014 & 1 & & I & & 1 & & & \\
\hline Etxeberria et $\mathrm{al}^{61}$ & 2020 & I & & I & & I & 1 & & \\
\hline Flujas-Contreras et a ${ }^{42}$ & 2019 & 1 & & 1 & & 1 & & & \\
\hline Hadjiconstantinou et al ${ }^{62}$ & 2016 & I & & I & & & 1 & & \\
\hline Harrer et $\mathrm{al}^{63}$ & 2019 & I & & 1 & & 1 & 1 & & \\
\hline Harris et $\mathrm{al}^{64}$ & 2020 & I & & 1 & & 1 & & & \\
\hline Hinojo-Lucena et $\mathrm{al}^{65}$ & 2019 & I & & & 1 & & & I & I \\
\hline Huang ${ }^{66}$ & 2010 & 1 & & & I & & & I & \\
\hline loannidis et $\mathrm{al}^{67}$ & 2019 & I & & & I & & & I & I \\
\hline Ivie et al ${ }^{68}$ & 2020 & I & & & I & & & I & \\
\hline Karimikia et $\mathrm{al}^{69}$ & 2020 & I & & & 1 & & & I & \\
\hline Kuo et al ${ }^{\prime}$ & 2018 & I & & I & & I & & & \\
\hline Lattie et $\mathrm{al}^{70}$ & 2019 & & 1 & 1 & & & 1 & & \\
\hline Linardon et $\mathrm{al}^{44}$ & 2019 & 1 & & 1 & & 1 & & & \\
\hline Liu et $\mathrm{al}^{71}$ & 2016 & 1 & & & 1 & & & I & \\
\hline Lunde et $\mathrm{al}^{72}$ & 2018 & & 1 & 1 & & 1 & & & \\
\hline Marino et $\mathrm{al}^{73}$ & 2018 & I & & & I & & & I & \\
\hline Noone et $\mathrm{al}^{74}$ & 2020 & I & & I & & 1 & & & \\
\hline Nowland et $\mathrm{al}^{20}$ & 2018 & & 1 & & 1 & 1 & & I & \\
\hline Rogers et $\mathrm{al}^{38}$ & 2017 & & I & & I & I & & & \\
\hline Sevilla-Llewellyn-Jones et $\mathrm{al}^{75}$ & 2018 & I & & I & & I & & & \\
\hline Sin et $\mathrm{al}^{39}$ & 2020 & I & & I & & I & & & \\
\hline Song et $\mathrm{al}^{76}$ & 2014 & I & & & 1 & & & I & \\
\hline Spijkerman et al ${ }^{77}$ & 2016 & I & & I & & I & & & \\
\hline Tokunaga ${ }^{78}$ & 2017 & I & & & 1 & & & I & \\
\hline
\end{tabular}

(Continued) 
Table 2 (Continued).

\begin{tabular}{|c|c|c|c|c|c|c|c|c|c|}
\hline Primary Author (Citation) & Year & $\mathbf{M}$ & $\mathbf{R}$ & $\mathbf{E}$ & C & IA+ & IAO & IA- & ID- \\
\hline Valimaki et $\mathrm{al}^{79}$ & 2016 & 1 & & I & & I & & & \\
\hline Valimaki et $\mathrm{al}^{36}$ & 2020 & I & & 1 & & I & & & \\
\hline Zhou et al ${ }^{80}$ & 2020 & I & & 1 & & I & & & \\
\hline Sum of counts & & 32 & 6 & 22 & 14 & 22 & 5 & I I & 4 \\
\hline
\end{tabular}

Note: Grey marked: evidence showing detrimental effects of internet activity on well-being, more information see Supplementary Table I.

Abbreviations: Year, year the study was published; M, meta-analysis; R, review; E, experimental/intervention study design; C, correlational study; IA+, internet activity positive; IA0, no correlation between internet activity and well-being; IA-, negative correlation between internet activity and well-being; ID-, internet dependency negative.

performing internet activities show less well-being over time. Clearly, there are negative effects of internet dependency and problematic internet use: also, just simple activity on the internet harbors the risk of harm if the internet activity becomes too intense. This is especially the case if the internet environment is not promoting long-term well-being but rather short-term rewards by positive stimuli (eg, internet gaming elicits positive emotions instantly, but in the long term, it may have negative effects). ${ }^{16}$

Interventions that employ the internet and help individuals to self-regulate risk the collateral damage of these negative effects, too, but little research could be found on this so far (risks, side effects or unwanted events/preventable adverse events). Interventions aiming at mental health in primary prevention and targeting well-being seem to have no effect or work positively, the latter especially if they are designed well. Thus, the extent to which internet activity is predictive for well-being depends on the internet activity itself: PIU and ID are detrimental for well-being while internet activity facilitating selfmanagement is beneficial. Furthermore, there seems to be an inverse u-shape relationship: the healthier the internet activity the better, but only until a level where it becomes too much and transforms into PIU or ID, ie, is adverse for well-being.

Previous findings show that positive effects of internet activity occur when individuals get support with performing health behaviors such as learning how to overcome negative emotions like loneliness and depression. Such behaviors also include physical activity. However, spending too much time with internet activities detracts from the positive effects. Thus, balancing different behaviors in concert might require more skills than changing single behaviors alone. While this might cause that multiple behavior change appears more difficult to change than to achieve a single behavior change,

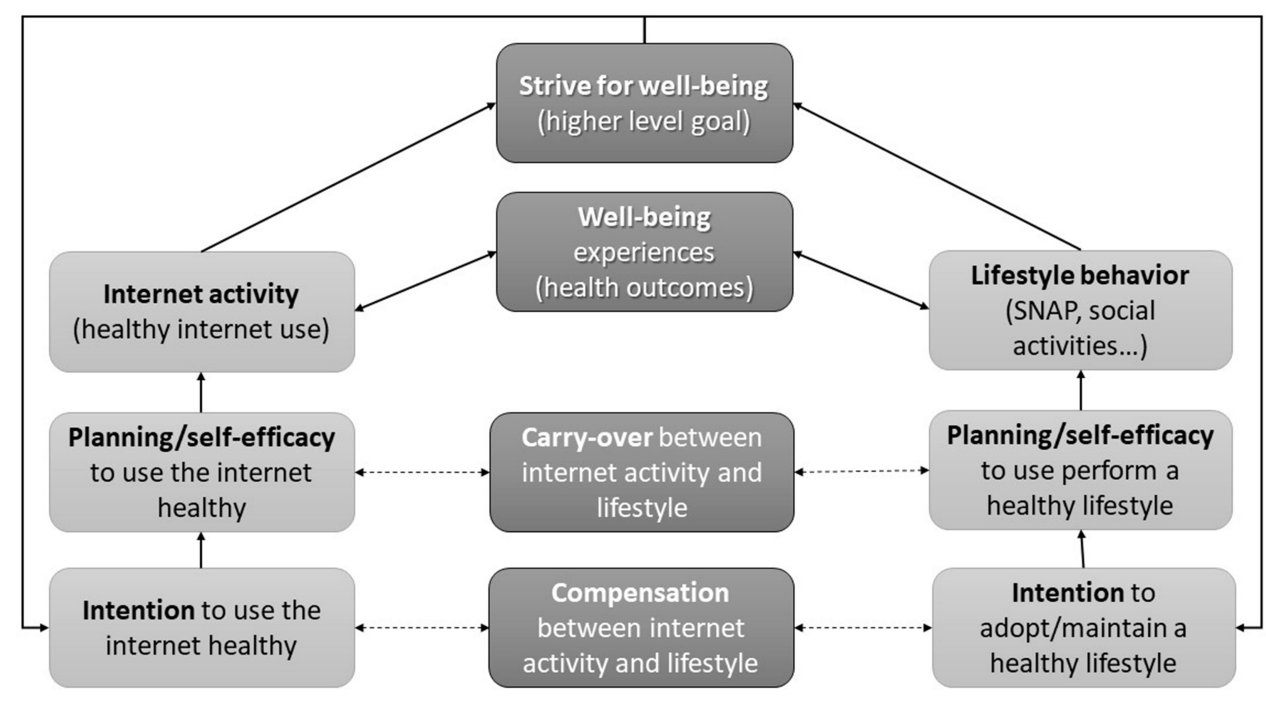

Figure I The compensatory carry-over action model applied to internet activity and lifestyle behavior (eg, SNAP, smoking, nutrition, alcohol, physical activity, and social participation). $^{2}$ 
these small improvements may have larger effects on outcomes such as workability, body weight and well-being. Accordingly, those outcomes should be considered, which is often not the case with the mainstream behavior change models (e.g., ${ }^{3,81}$ ). One of the few theories which discuss the currently faced lack of evidence on comprehensive theories of multiple behavior change is the Compensatory CarryOver Action Model (CCAM). ${ }^{2}$

\section{The Compensatory Carry-Over Action Model}

We searched different electronic databases including Web of Science and Google Scholar for the "Compensatory CarryOver Action Model" but only report here a selected sample for all hits due to brevity: No systematic review or metaanalysis was planned at this point in time as a scoping review appeared more appropriate to scan the state of the science and to give a broad overview of the model.

The key idea of the CCAM is that experiences/health outcomes like well-being result from different behaviors such as internet activity and lifestyle behaviors (eg, physical activity, nutrition). These experiences/health outcomes feedback into behavior management by functioning like outcome expectations but also by having an impact on higher-level goals. Such higher-level goals drive behavior management centrally as individuals can explicitly or implicitly aim for improving their well-being by means of performing actions in that sense (see Figure 1).

Moreover, the CCAM stems from the tradition of socialcognitive models of behavior change and thereby, models' behaviors adoption and maintenance detailed by different variables and mechanisms, which are already well known from other theories and models..$^{3,31,51}$ The CCAM states that individuals who perform a risk behavior may believe that they can compensate for this by performing another behavior.

Evidence for these cognitive processes has been found (eg, Storm et al). ${ }^{82}$ While compensation ie, compensatory cognitions were generally negative for adherence, research has also shown that intrinsic motivation can lower the risks for a lapse due to compensatory cognitions. ${ }^{83}$ This indicates that general beliefs about the interrelationship between behaviors, so-called higher-level goals, determine lifestyle changes. Higher-level goals can volitionally or unconsciously drive different behaviors and their predictors.

Higher-level goals become concrete by means of different behaviors, which are subjectively regarded as feeding into this goal. One example is modulating the outcome of type 2 diabetes: the achievement of well-being due to tracking of the blood parameter $\mathrm{HbA}_{1 \mathrm{c}}$ (representing the success of treatment of the last months) by means of an App and lifestyle changes including physical activity is related to the higher-level goals of well-being.

These two behaviors must typically be intended, planned, and translated into actions. Higher-level goals can also feed into outcome expectancies, and thereby drive behavior via intention formation. Compensation, ie, compensatory cognitions, comes into play in the case of a tempting situation occurs: if behavior A (eg, going for a walk) is hindered by behavior B (eg, participating in an online training on how to do the $\mathrm{HbA}_{1 \mathrm{c}}$ tracking), one can decide to perform another behavior (behavior $\mathrm{C}$; eg, performing back exercises during the online training). Alternatively, one can adapt the performance of behavior A in terms of executing behavior A later or in another way (eg, walking after the training or running the next morning).

Evidence on the effectiveness of the latter stems from the coping planning literature. ${ }^{3,81}$ Both compensatory intentions serve the purpose of compensating for the nonperformance of the originally intended behavior. The key is that an awareness of the risk of an unhealthy lifestyle must exist to at least a moderate degree. The person has to intend to perform the behavior, ie, not to perform the risk behavior. Thus, previous intentions and behaviors (also called "stages of change") ${ }^{31}$ come into play. Individuals with high intentions but no previous behavior performance are those individuals most at risk for not translating their healthy intentions into behavior. A previous study found that this may be related to insufficient planning, a lack of self-efficacy and too low intentions. ${ }^{82}$

Individuals with strong habits are less at risk of being distracted from their cognitive preparation. Thus, it is imperative to distinguish between two groups: group 1 with those individuals who are experienced with behavior B, and group 2 with those for whom behavior B is completely new. Whereas group 1 has a higher likelihood of successfully translating intentions into behavior, group 2, without previous behavior experience, is compelled to invest more volitional control and is more at risk for not translating intentions (due to compensatory cognitions, CC) into action.

Individuals most at risk for not translating their good (new) intentions into behavior are the ones with insufficient intentions, planning and self-efficacy, as well as those being exposed to non-supportive situational 
temptations. This is true for every single behavior, however, when looking at different behaviors in orchestration, previous experience, skills and resources from one behavior can also be carried over to another behavior. In other words, the key determinant for turning the lapses of behavior A into an initiative with behavior B depends not only on CCs and previous skills with behavior B but also on whether individuals can draw on behavior A's experiences and use the accordingly developed skills (eg, planning) and resources (eg, self-efficacy) or not. If such skills exist in behavior $\mathrm{A}$, then they might be carried-over to behavior B and vice versa - regardless of whether behavior $\mathrm{B}$ is intended due to $\mathrm{CCs}$ or other forces.

Interference of $\mathrm{CC}$ with other behavioral predictors was confirmed by a study, in which occupational flu shot participation for field workers at risk for being exposed to flu infections was investigated. ${ }^{84}$ The intervention targeted increasing flu shot participation by a planning intervention. It was found that an increased likelihood for employees' behavior performance was only successful for those individuals with low compensatory cognitions (ie, not believing that it would be sufficient to perform physical activity and eating healthy). The strongest predictors for later behavior were in line with the previous research: ${ }^{81}$ previous behavior and behavioral intentions. It can be assumed that those with high intentions and previous behavioral habits were much more likely to benefit from the action planning and coping planning intervention, and therefore not to develop compensatory cognitions. If individuals in the intervention group developed compensatory cognitions, they were as likely to perform the goal behavior as the standard control group addressing only the goal-setting. ${ }^{84}$ In this study, however, CCs were not targeted directly, which researchers should investigate further in the future.

Other factors that work specifically in the volitional processes of behavior change are carry-over between different behaviors. Carry-over is also known as transfer ${ }^{85}$ effects. One can measure carry-over as mechanisms carrying over resources from one domain to another or in terms of one behavior serving as a gateway for another. ${ }^{86,87}$ Generally, experience, skills, knowledge, and selfefficacy can be carried over from one behavior to another. While a substantial amount of research exists on transfer in educational and occupational areas, studies in the behavior domain testing transfer and comparable concepts are comparatively few.
Overall, the CCAM consists of the following five axioms: (1) Different behaviors (such as physical activity and internet activity) interrelate. (2) Higher-level goals (eg, striving for well-being) drive different behaviors by initiating and strengthening behavior-specific intentions. (3) Within each behavior domain, individuals translate their intentions into behavior via planning. Self-efficacy is a significant moderator of planning, and additionally affects behavior. (4) Behavior-specific processes for behavior A (physical activity) and behavior B (internet activity) interrelate via carry-over mechanisms and via compensation ie, compensatory cognitions. (5) A healthy lifestyle consists of multiple behaviors, which buffer the stress response (eg, due to chronic health limitations/disabilities, an acute infection or regional orders) and increase wellbeing. Single studies support specific assumptions and axioms (e.g., ${ }^{15,22,31,82,84,86-88}$ ). For instance, there is evidence supporting the assumption that carry-over mechanisms exist and showing that cognitive carry-over, as well as behavioral outcomes, depends on whether physicalactivity resources are being transferred to nutrition behavior. $^{86,87}$

Digital psychology research making use of internet activity (eg, online questionnaires, computer-assisted telephone interviews as specialized internet applications) and eHealth approaches are state-of-the-science approaches. This is because they provide different advantages including the use of artificial intelligence/machine learning and the administration of international, cross-cultural studies in different languages much easier than analog studies: interventions can be delivered in different languages, regions, and contexts. At the same time, risks and adverse effects related to digital devices should be considered (see Table 1). As such, privacy, data security and social media dependency (PIU, ID) are important to consider. Accordingly, this and other risks, side effects or unwanted events/preventable adverse events should be considered when fostering internet activity to improve well-being. Further suggestions will follow in the next section.

\section{Limitations, Implications, and Suggestions for Future Research}

This review has shown that there are several studies examining the connection between well-being and internet activity, but only a few studies using and evaluating a theoretical background. The CCAM represents a theoretical background that can be used to explain 
multiple behavior change. More original research is still required, however, to extend the validation of the construct and assumptions of the CCAM. This needs to be done using different research designs, including RCTs (which are the gold standard testing effects experimentally) testing effects in contrast to an active control group to prevent a pure treatment effect. Only after this occurs aggregation in terms of a systematic review or meta-analysis is appropriate. However, the findings on the extent of internet activity being predictive for psychological well-being from this scoping review set the stage for further work including a systematic review or employing a metaanalytical methodology. Planning for that requires an according trial registration and sufficient resources to appropriately conduct such a study.

We suggest future research to employ explicitly the theoretical contexts like the CCAM and testing effects in intervention designs. Furthermore, individuals should be supported in different settings to perform internet activities and with that their well-being. Also, the internet opens many options for research aims that are hardly feasible through analog approaches. In that sense, digital psychology research (eg, online questionnaires, computer-assisted telephone interviews as specialized web applications) and eHealth approaches are state-of-the-science approaches and the advantageous effects exist.

At the same time, risks and adverse effects related to digital devices should be considered, such as privacy and data security as well as PIU, ID and social media dependency. Especially PIU, ID and social media dependency hinders long-term well-being when the internet is used too intense or too often. Behavior management and learning should aim for preventing risky internet activities and promoting a mode of internet activity that keeps the aim of maintaining and improving well-being on the agenda. Taking individuals' mental health and especially overcoming problematic internet use or internet dependency into account is required when employing internet-based interventions. For instance, this could be done by designing internet applications not too enjoyable/pleasuring with a medium level of rewarding stimuli only. Besides overreliance on intervention apps, solutions (eg, suitable instructions) to eliminate the increased anxiety resulting from self-diagnosis using apps should also be considered. $^{89}$ Also, making individuals aware of the risk of PIU and internet dependency as well as implementing behavioral cues to exit in face of too much IU, or debriefing internet users at risk for PIU and internet dependency regarding analog alternatives to digital modes. Studies in this area are recommended considering not only psychological characteristics to develop self-regulatory strategies (eg, increase self-administered behavior planning), but also the social supports (eg, friends and family) to reduce the risk of PIU. In addition, psychological interventions that aim to avoid PIU or reduce addiction severity are recommended basing on an effective theory, such as CCAM, to identify the indicators from multiple behaviors, thus develop intervention applications and avoid adverse side effects (eg, creating alternative addictive behaviors). Moreover, such effects for other multiple behavior domains, as well as the interrelations of behaviors in a changing setting, still need to be evaluated further. More research is also needed in comparing different intervention modes (such as computer-, internet- or telephone-delivered interventions), as well as in evaluating long-term effects and impacts on other outcomes, such as changes in health status and diseases' outcome beside indicators of well-being.

\section{Conclusion}

This review shows the strong connection between internet activity and psychological well-being as demonstrated in several studies. Thus, internet activity influences psychological well-being and can be influenced by healthy behavior in positive or negative ways.

To explain the theoretical background in terms of multiple behavior change the CCAM proposes that higher-level goals drive behavior management centrally as individuals aim for improving their well-being by means of performing actions in that sense. To summarizing, the few studies testing the CCAM or selected aspects of it including internet activity and well-being demonstrate the potentials of such a multifactorial, sophisticated approach. Also, applications based on the CCAM have practical use supporting the long-term multimodal treatment.

Internet-based interventions, especially as one pillar of long-term multimodal treatment, have a high potential to improve health promotion, prevention, treatment, and rehabilitation. Specifically, challenges can be met by internet activities: eg, demographic change (with diverse needs and varying skills of users), lack of personnel resources in the health care systems, and the COVID-19 pandemic with its restrictions in delivering analog therapies: interventions delivered via the internet provide the option to substitute or to be added to the existing analog therapies. Furthermore, these internet-based interventions can take different behaviors into account. This 
leads to individually tailored therapy strategies that have an enormous potential to optimize the existing health care and to improve the outcome, especially of chronic diseases. This significance of research results for an individual's mental health, especially in overcoming the problem of using the internet, should be considered when employing internetbased interventions.

\section{Acknowledgments}

We would like to thank Ronja Bellinghausen for supporting us with literature search, manuscript editing and proofreading. We also appreciate the support of Kureva Matuku by performing parts of the scoping search of published studies.

\section{Disclosure}

The authors report no conflicts of interest in this work.

\section{References}

1. Kuo CC, Su YJ, Lin CC. A systematic review and meta-analysis: effectiveness of internet empowerment-based self-management interventions on adults with metabolic diseases. $J$ Adv Nurs. 2018;74 (8):1787-1802. doi:10.1111/jan.13574

2. Lippke S. Modelling and supporting complex behavior change related to obesity and diabetes prevention and management with the Compensatory Carry-Over Action Model. J Diabetes Obes. 2014;1 (2):1-5. doi:10.15436/2376-0494.14.009

3. Rhodes RE, de Bruijn GJ. How big is the physical activity intentionbehaviour gap? A meta-analysis using the action control framework Br J Health Psychol. 2013;18(2):296-309. doi:10.1111/bjhp.12032

4. Diener E. Subjective well-being: the science of happiness and a proposal for a national index. Am Psychol. 2000;55(1):34. doi:10.1037/0003-066X.55.1.34

5. Shin DC, Johnson DM. Avowed happiness as an overall assessment of the quality of life. Soc Indic Res. 1978;5(1-4):475-492. doi:10.1007/BF00352944

6. Seligman ME. Flourish: A Visionary New Understanding of Happiness and Well-Being. Simon and Schuster; 2012.

7. Westerhof GJ, Keyes CL. Mental illness and mental health: the two continua model across the lifespan. $J$ Adult Dev. 2010;17(2):110-119. doi:10.1007/s10804-009-9082-y

8. Ikeda A, Steptoe A, Shipley M, et al. Psychological wellbeing and aortic stiffness: longitudinal study. Hypertension. 2020;76 (3):675-682. doi:10.1161/HYPERTENSIONAHA.119.14284

9. Hofer M, Hargittai E, Büchi M, Seifert A. Older adults' online information seeking and subjective well-being: the moderating role of internet skills. Int J Commun. 2019;13:18.

10. Serper M, Patzer RE, Curtis LM, et al. Health literacy, cognitive ability, and functional health status among older adults. Health Serv Res. 2014;49(4):1249-1267. doi:10.1111/1475-6773.12154

11. VanderWeele TJ, Hawkley LC, Cacioppo JT. On the reciprocal association between loneliness and subjective well-being. $\mathrm{Am}$ J Epidemiol. 2012;176(9):777-784. doi:10.1093/aje/kws173

12. House JS. Social isolation kills, but how and why? Psychosom Med. 2001;63(2):273-274. doi:10.1097/00006842-200103000-00011

13. Kim J, LaRose R, Peng W. Loneliness as the cause and the effect of problematic internet use: the relationship between internet use and psychological well-being. Cyberpsychol Behav. 2009;12(4):451-455. doi: $10.1089 / \mathrm{cpb} .2008 .0327$
14. Wang L, Luo J, Bai Y, et al. Internet addiction of adolescents in China: prevalence, predictors, and association with well-being. Addict Res Theory. 2013;21(1):62-69. doi:10.3109/16066359.20 12.690053

15. Gao L, Gan Y, Whittal A, Yan S, Lippke S. The mediator roles of problematic internet use and perceived stress between health behaviors and work-life balance among internet users in Germany and China: web-based cross-sectional study. J Med Internet Res. 2020;22 (5):e16468. doi:10.2196/16468

16. Kuss DJ. Internet gaming addiction: current perspectives. Psychol Res Behav Manag. 2013;6:125. doi:10.2147/PRBM.S39476

17. Thomas Craig KJ, Morgan LC, Chen CH, et al. Systematic review of context-aware digital behavior change interventions to improve health. Transl Behav Med. 2020. doi:10.1093/tbm/ibaa099

18. Marino C, Gini G, Vieno A, Spada MM. The associations between problematic Facebook use, psychological distress and well-being among adolescents and young adults: a systematic review and meta-analysis. J Affect Disord. 2018;226:274-281. doi:10.1016/j. jad.2017.10.007

19. Cikrikci Ö. The effect of internet use on well-being: meta-analysis. Comput Human Behav. 2016;65:560-566. doi:10.1016/j.chb.201 6.09 .021

20. Nowland R, Necka EA, Cacioppo JT. Loneliness and social internet use: pathways to reconnection in a digital world? Perspect Psychol Sci. 2018;13(1):70-87. doi:10.1177/1745691617713052

21. Noble N, Paul C, Turon H, Oldmeadow C. Which modifiable health risk behaviours are related? A systematic review of the clustering of Smoking, Nutrition, Alcohol and Physical activity ('SNAP') health risk factors. Prev Med. 2015;81:16-41. doi:10.1016/j. ypmed.2015.07.003

22. Gao L, Gan Y, Lippke S. Multiple health behaviors across age: physical activity and internet use. Am J Health Behav. 2020;44 (3):333-344. doi:10.5993/AJHB.44.3.6

23. Hennemann S, Farnsteiner S, Sander L. Internet-and mobile-based aftercare and follow-up for mental disorders: protocol of a systematic review and meta-analysis. BMJ Open. 2017;7(6):e016696. doi:10.1136/bmjopen-2017-016696

24. Lam SS, Jivraj S, Scholes S. Exploring the relationship between internet use and mental health among older adults in England: longitudinal observational study. J Med Internet Res. 2020;22(7):e15683. doi: $10.2196 / 15683$

25. Kim C, Shen C. Connecting activities on Social Network Sites and life satisfaction: a comparison of older and younger users. Comput Human Behav. 2020;105:106222. doi:10.1016/j.chb.2019.106222

26. Szabo A, Allen J, Stephens C, Alpass F. Longitudinal analysis of the relationship between purposes of internet use and well-being among older adults. Gerontologist. 2019;59(1):58-68. doi:10.1093/geront/ gny036

27. Ko NY, Lu WH, Chen YL, et al. COVID-19-related information sources and psychological well-being: an online survey study in Taiwan. Brain Behav Immun. 2020;87:153-154. doi:10.1016/j. bbi.2020.05.019

28. Torous J, Myrick KJ, Rauseo-Ricupero N, Firth J. Digital mental health and COVID-19: using technology today to accelerate the curve on access and quality tomorrow. JMIR Ment Health. 2020;7(3): e18848. doi:10.2196/18848

29. Costa RM, Patrão I, Machado M. Problematic internet use and feelings of loneliness. Int J Psychiatry Clin Pract. 2019;23(2):160-162. doi:10.1080/13651501.2018.1539180

30. Liu D, Baumeister RF, Yang CC, Hu B. Digital communication media use and psychological well-being: a meta-analysis. JCMC. 2019;24(5):259-273. doi:10.1093/jcmc/zmz013

31. Lippke S, Nigg CR, Maddock JE. Health-promoting and health-risk behaviors: theory-driven analyses of multiple health behavior change in three international samples. Int J Behav Med. 2012;19(1):1-3. doi:10.1007/s12529-010-9135-4 
32. Fleary SA, Nigg CR. Trends in health behavior patterns among US adults, 2003-2015. Ann Behav Med. 2019;53(1):1-5. doi:10.1093/ $\mathrm{abm} / \mathrm{kay} 010$

33. Kvaavik E, Batty GD, Ursin G, Huxley R, Gale CR. Influence of individual and combined health behaviors on total and cause-specific mortality in men and women: the United Kingdom health and lifestyle survey. Arch Intern Med. 2010;170(8):711-718. doi:10.1001/ archinternmed.2010.76

34. Heidemann C, Scheidt-Nave C. Prävalenz, Inzidenz und Mortalität von Diabetes mellitus bei Erwachsenen in Deutschland - bestandsaufnahme zur Diabetes-Surveillance. J Health Monit. 2017;2(3). doi:10.17886/RKI-GBE-2017-050

35. Arnberg FK, Linton SJ, Hultcrantz M, Heintz E, Jonsson U. Internetdelivered psychological treatments for mood and anxiety disorders: a systematic review of their efficacy, safety, and cost-effectiveness. PLoS One. 2014;9(5):e98118. doi:10.1371/journal.pone.0098118

36. Valimaki M, Anttila K, Anttila M, Lahti M. Web-based interventions supporting adolescents and young individuals with depressive symptoms: systematic review and meta-analysis. JMIR mHealth uHealth. 2017;5(12):e180. doi:10.2196/mhealth.8624

37. Norman CD, Skinner HA. eHEALS: the eHealth literacy scale. J Med Internet Res. 2006;8(4):e27. doi:10.2196/jmir.8.4.e27

38. Rogers MA, Lemmen K, Kramer R, Mann J, Chopra V. Internetdelivered health interventions that work: systematic review of meta-analyses and evaluation of website availability. $J$ Med Internet Res. 2017;19(3):e90. doi:10.2196/jmir.7111

39. Sin J, Galeazzi G, McGregor E, et al. Digital Interventions for screening and treating common mental disorders or symptoms of common mental illness in adults: systematic review and meta-analysis. $J$ Med Internet Res. 2020;22(9):e20581. doi:10.2196/20581

40. Webb T, Joseph J, Yardley L, Michie S. Using the internet to promote health behavior change: a systematic review and meta-analysis of the impact of theoretical basis, use of behavior change techniques, and mode of delivery on efficacy. $J$ Med Internet Res. 2010;12(1):e4. doi:10.2196/jmir.1376

41. Lustria ML, Noar SM, Cortese J, Van Stee SK, Glueckauf RL, Lee J. A meta-analysis of web-delivered tailored health behavior change interventions. J Health Commun. 2013;18(9):1039-1069. doi:10.10 80/10810730.2013.768727

42. Flujas-Contreras JM, García-Palacios A, Gómez I. Technology-based parenting interventions for children's physical and psychological health: a systematic review and meta-analysis. Psychol Med. 2019;49(11):1787-1798. doi:10.1017/S0033291719000692

43. Marcus BH, Nigg CR, Riebe D, Forsyth LH. Interactive communication strategies: implications for population-based physical-activity promotion. Am J Prev Med. 2000;19(2):121-126. doi:10.1016/ S0749-3797(00)00186-0

44. Linardon J, Cuijpers P, Carlbring P, Messer M, Fuller-Tyszkiewicz M. The efficacy of app-supported smartphone interventions for mental health problems: a meta-analysis of randomized controlled trials. World Psychiatry. 2019;18(3):325-336. doi:10.1002/wps.20673

45. Clark DM, Canvin L, Green J, Layard R, Pilling S, Janecka M. Transparency about the outcomes of mental health services (IAPT approach): an analysis of public data. Lancet. 2018;391 (10121):679-686. doi:10.1016/S0140-6736(17)32133-5

46. Cuijpers P, Marks IM, van Straten A, Cavanagh K, Gega L, Andersson G. Computer-aided psychotherapy for anxiety disorders: a meta-analytic review. Cogn Behav Ther. 2009;38(2):66-82. doi:10.1080/16506070802694776

47. Richards D, Richardson T. Computer-based psychological treatments for depression: a systematic review and meta-analysis. Clin Psychol Rev. 2012;32(4):329-342. doi:10.1016/j.cpr.2012.02.004

48. Jacobi F, Höfler M, Strehle J, et al. Psychische Störungen in der Allgemeinbevölkerung. Der Nervenarzt. 2014;85(1):77-87. doi:10.1007/s00115-013-3961-y
49. Jacobi F, Höfler M, Strehle J, et al. Erratum zu: psychische Störungen in der Allgemeinbevölkerung. Studie zur Gesundheit Erwachsener in Deutschland und ihr Zusatzmodul, Psychische Gesundheit "(DEGS1MH). Der Nervenarzt. 2016;87(1):88-90. doi:10.1007/s00115-015-4458-7

50. Weymann N, Dirmaier J, Von Wolff A, Kriston L, Härter M. Effectiveness of a Web-based tailored interactive health communication application for patients with type 2 diabetes or chronic low back pain: randomized controlled trial. J Med Internet Res. 2015;17(3): e53. doi:10.2196/jmir.3904

51. Geller K, Lippke S, Nigg CR. Future directions of multiple behavior change research. J Behav Med. 2017;40(1):194-202. doi:10.1007/ s10865-016-9809-8

52. Rooke S, Thorsteinsson E, Karpin A, Copeland J, Allsop D. Computer-delivered interventions for alcohol and tobacco use: a meta-analysis. Addiction. 2010;105(8):1381-1390. doi:10.1111/ j.1360-0443.2010.02975.x

53. Brown M, Glendenning AC, Hoon AE, John A. Effectiveness of web-delivered acceptance and commitment therapy in relation to mental health and well-being: a systematic review and meta-analysis. J Med Internet Res. 2016;18(8):e221. doi:10.2196/jmir.6200

54. Carolan S, Harris PR, Cavanagh K. Improving employee well-being and effectiveness: systematic review and meta-analysis of web-based psychological interventions delivered in the workplace. $J$ Med Internet Res. 2017;19(7):e271. doi:10.2196/jmir.7583

55. Chan KL, Chen M. Effects of social media and mobile health apps on pregnancy care: meta-analysis. JMIR mHealth uHealth. 2019;7(1): e11836. doi:10.2196/11836

56. Cheng $\mathrm{C}, \mathrm{Li} \mathrm{AY}$. Internet addiction prevalence and quality of (real) life: a meta-analysis of 31 nations across seven world regions. Cyberpsychol Behav Soc Netw. 2014;17(12):755-760. doi:10.1089/ cyber.2014.0317

57. Cheng YS, Tseng PT, Lin PY, et al. Internet addiction and its relationship with suicidal behaviors: a meta-analysis of multinational observational studies. J Clin Psychiatry. 2018;79(4). doi:10.4088/ JCP.17r11761

58. Choi M, Kong S, Jung D. Computer and internet interventions for loneliness and depression in older adults: a meta-analysis. Healthc Inform Res. 2012;18(3):191-198. doi:10.4258/hir.2012.18.3.191

59. Cowpertwait L, Clarke D. Effectiveness of web-based psychological interventions for depression: a meta-analysis. Int $J$ Ment Health Addict. 2013;11(2):247-268. doi:10.1007/s11469-012-9416-z

60. Davies EB, Morriss R, Glazebrook C. Computer-delivered and web-based interventions to improve depression, anxiety, and psychological well-being of university students: a systematic review and meta-analysis. $J$ Med Internet Res. 2014;16(5):e130. doi:10.2196/ jmir.3142

61. Etxeberria I, Salaberria K, Gorostiaga A. Online support for family caregivers of individuals with dementia: a systematic review and meta-analysis of RCTs and quasi-experimental studies. Aging Ment Health. 2020;1-6. doi:10.1080/13607863.2020.1758900

62. Hadjiconstantinou M, Byrne J, Bodicoat DH, et al. Do web-based interventions improve well-being in type 2 diabetes? A systematic review and meta-analysis. $J$ Med Internet Res. 2016;18(10):e270. doi:10.2196/jmir.5991

63. Harrer M, Adam SH, Baumeister $\mathrm{H}$, et al. Internet interventions for mental health in university students: a systematic review and metaanalysis. Int $J$ Methods Psychiatr Res. 2019;28(2):e1759. doi:10.1002/mpr.1759

64. Harris M, Andrews K, Gonzalez A, Prime H, Atkinson L. Technology-assisted parenting interventions for families experiencing social disadvantage: a meta-analysis. Preven Sci. 2020;21:714-727. doi:10.1007/s11121-020-01128-0

65. Hinojo-Lucena FJ, Aznar-Díaz I, Cáceres-Reche MP, Trujillo-Torres JM, Romero-Rodríguez JM. Problematic internet use as a predictor of eating disorders in students: a systematic review and meta-analysis study. Nutrients. 2019;11(9):2151. doi:10.3390/nu11092151 
66. Huang C. Internet use and psychological well-being: a meta-analysis. Cyberpsychol Behav Soc Netw. 2010;13(3):241-249. doi:10.1089/ cyber.2009.0217

67. Ioannidis K, Hook R, Goudriaan AE, et al. Cognitive deficits in problematic internet use: meta-analysis of 40 studies. $\mathrm{Br}$ J Psychiatry. 2019;215(5):639-646. doi:10.1192/bjp.2019.3

68. Ivie EJ, Pettitt A, Moses LJ, Allen NB. A meta-analysis of the association between adolescent social media use and depressive symptoms. J Affect Disord. 2020;275:165-174. doi:10.1016/j. jad.2020.06.014

69. Karimikia H, Singh H, Joseph D. Negative outcomes of ICT use at work: meta-analytic evidence and the role of job autonomy. Int Res. 2020; ahead-of-print. doi:10.1108/INTR-09-2019-0385

70. Lattie EG, Adkins EC, Winquist N, Stiles-Shields C, Wafford QE, Graham AK. Digital mental health interventions for depression, anxiety, and enhancement of psychological well-being among college students: systematic review. J Med Internet Res. 2019;21(7):e12869. doi: $10.2196 / 12869$

71. Liu D, Baumeister RF. Social networking online and personality of self-worth: a meta-analysis. J Res Pers. 2016;64:79-89. doi:10.1016/ j.jrp.2016.06.024

72. Lunde P, Nilsson BB, Bergland A, Kværner KJ, Bye A. The effectiveness of smartphone apps for lifestyle improvement in noncommunicable diseases: systematic review and meta-analyses. $\mathrm{J}$ Med Internet Res. 2018;20(5):e162. doi:10.2196/jmir.9751

73. Marino C, Gini G, Vieno A, Spada MM. A comprehensive meta-analysis on problematic Facebook use. Comput Human Behav. 2018;83:262-277. doi:10.1016/j.chb.2018.02.009

74. Noone C, McSharry J, Smalle M, et al. Video calls for reducing social isolation and loneliness in older individuals: a rapid review. Cochrane Database Syst Rev. 2020;(5).

75. Sevilla-Llewellyn-Jones J, Santesteban-Echarri O, Pryor I, McGorry P, Alvarez-Jimenez M. Web-based mindfulness interventions for mental health treatment: systematic review and meta-analysis. JMIR Ment Health. 2018;5(3):e10278. doi:10.2196/10278

76. Song H, Zmyslinski-Seelig A, Kim J, et al. Does Facebook make you lonely? A meta analysis. Comput Human Behav. 2014;36 (36):446-452. doi:10.1016/j.chb.2014.04.011

77. Spijkerman MP, Pots WT, Bohlmeijer ET. Effectiveness of online mindfulness-based interventions in improving mental health: a review and meta-analysis of randomised controlled trials. Clin Psychol Rev. 2016;45:102-114. doi:10.1016/j.cpr.2016.03.009

78. Tokunaga RS. A meta-analysis of the relationships between psychosocial problems and internet habits: synthesizing internet addiction, problematic internet use, and deficient self-regulation research. Commun Monogr. 2017;84(4):423-446. doi:10.1080/03637751.2017.1332419
79. Valimaki M, Athanasopoulou C, Lahti M, Adams CE. Effectiveness of social media interventions for individuals with schizophrenia: a systematic review and meta-analysis. J Med Internet Res. 2016;18 (4):e92. doi:10.2196/jmir.5385

80. Zhou C, Hu H, Wang C, et al. The effectiveness of mHealth interventions on postpartum depression: a systematic review and meta-analysis. J Telemed Telecare. 2020;1357633X20917816. doi:10.1177/1357633X20917816

81. Webb TL, Sheeran P. Does changing behavioral intentions engender behavior change? A meta-analysis of the experimental evidence. Psychol Bull. 2006;132(2):249. doi:10.1037/0033-2909.132.2.249

82. Storm V, Reinwand D, Wienert J, Kuhlmann T, De Vries H, Lippke S. Brief report: compensatory health beliefs are negatively associated with intentions for regular fruit and vegetable consumption when self-efficacy is low. J Health Psychol. 2017;22(8):1094-1100. doi:10.1177/1359105315625358

83. Miquelon P, Knäuper B, Vallerand RJ. Motivation and goal attainment. The role of compensatory beliefs. Appetite. 2012;58 (2):608-615. doi:10.1016/j.appet.2011.12.025

84. Ernsting A, Schwarzer R, Lippke S, Schneider M. 'I do not need a flu shot because I lead a healthy lifestyle': compensatory health beliefs make vaccination less likely. J Health Psychol. 2013;18(6):825-836. doi:10.1177/1359105312455076

85 . Barnett SM, Ceci SJ. When and where do we apply what we learn? A taxonomy for far transfer. Psychol Bull. 2002;128(4):612. doi:10.1037/0033-2909.128.4.612

86. Fleig L, Kerschreiter R, Schwarzer R, Pomp S, Lippke S. 'Sticking to a healthy diet is easier for me when I exercise regularly': cognitive transfer between physical exercise and healthy nutrition. Psychol Health. 2014;29 (12):1361-1372. doi:10.1080/08870446.2014.930146

87. Fleig L, Lippke S, Pomp S, Schwarzer R. Intervention effects of exercise self-regulation on physical exercise and eating fruits and vegetables: a longitudinal study in orthopedic and cardiac rehabilitation. Prev Med. 2011;53(3):182-187. doi:10.1016/j.ypmed.2011.06.019

88. Cihlar V, Lippke S. Physical activity behavior and competing activities: interrelations in 55-to 70-year-old Germans. J Aging Phys Act. 2017;25(4):576-586. doi:10.1123/japa.2016-0211

89. Leigh S, Flatt S. App-based psychological interventions: friend or foe? Evid Based Ment Health. 2015;18(4):97-99. doi:10.1136/eb2015-102203
Psychology Research and Behavior Management

\section{Publish your work in this journal}

Psychology Research and Behavior Management is an international, peer-reviewed, open access journal focusing on the science of psychology and its application in behavior management to develop improved outcomes in the clinical, educational, sports and business arenas. Specific topics covered in the journal include: Neuroscience, memory and decision making; Behavior modification and management; Clinica applications; Business and sports performance management; Social and developmental studies; Animal studies. The manuscript management system is completely online and includes a very quick and fair peer-review system, which is all easy to use. Visit http://www. dovepress.com/testimonials.php to read real quotes from published authors. 